\title{
Convergence in Multispecies Interactions
}

\section{Citation}

Bittleston, Leonora S., Naomi E. Pierce, Aaron M. Ellison, and Anne Pringle. 2016. "Convergence in Multispecies Interactions." Trends in Ecology \& Evolution (February). doi:10.1016/ j.tree.2016.01.006.

\section{Published Version}

10.1016/j.tree.2016.01.006

\section{Permanent link}

http://nrs.harvard.edu/urn-3:HUL.InstRepos:25620508

\section{Terms of Use}

This article was downloaded from Harvard University's DASH repository, and is made available under the terms and conditions applicable to Open Access Policy Articles, as set forth at http:// nrs.harvard.edu/urn-3:HUL.InstRepos:dash.current.terms-of-use\#OAP

\section{Share Your Story}

The Harvard community has made this article openly available.

Please share how this access benefits you. Submit a story.

Accessibility 
Title: Convergence in multispecies interactions

Authors: Leonora S. Bittleston ${ }^{1,2}$, Naomi E. Pierce ${ }^{1,2}$, Aaron M. Ellison ${ }^{1,3}$ and Anne Pringle ${ }^{4}$

\section{Addresses:}

${ }^{1}$ Department of Organismic and Evolutionary Biology, Harvard University, 16 Divinity Avenue, Cambridge, MA 02138 USA

${ }^{2}$ Museum of Comparative Zoology, Harvard University, 26 Oxford Street, Cambridge, MA, USA

${ }^{3}$ Harvard Forest, Harvard University, 324 North Main Street, Petersham, MA 01366 USA

${ }^{4}$ Departments of Bacteriology and Botany, University of Wisconsin-Madison, 430 Lincoln Drive, Madison, WI 53706 USA

Corresponding author: Bittleston, L.S. (lbittles@fas.harvard.edu)

Keywords: Community ecology; convergent evolution; microbe; mutualism; symbiosis.

Word counts: Abstract $=118 ;$ Main text $=3779 ;$ Box $1=377$; Box $2=370$; Box 3 (Outstanding Questions) $=162$.

Number of references: 89

Number of figures and tables: 1 Figure (plus 2 figures in Box 1), and 1 Table. 


\begin{abstract}
:
The concepts of convergent evolution and community convergence highlight how selective pressures can shape unrelated organisms or communities in similar ways. We propose a related concept, convergent interactions, to describe the independent evolution of multispecies interactions with similar physiological or ecological functions. A focus on convergent interactions clarifies how natural selection repeatedly favors particular kinds of associations among species. Characterizing convergent interactions in a comparative context is likely to facilitate prediction of the ecological roles of organisms (including microbes) in multispecies interactions, and selective pressures acting in poorly understood or newly discovered multispecies systems. We illustrate the concept of convergent interactions with examples: vertebrates and their gut bacteria; ectomycorrhizae; insect-fungal-bacterial interactions; pitcherplant food webs; and ants and ant-plants.
\end{abstract}




\section{Convergence in evolution and ecology}

The word convergence typically describes convergent evolution, the independent evolution of similar traits in different lineages resulting from strong selective pressures: "[a]nimals, belonging to two most distinct lines of descent, may readily become adapted to similar conditions, and thus assume a close external resemblance..." [1]. Although convergent evolution is primarily a descriptor of morphological features of animals and plants, it can be used to describe microbes and physiological processes as well (e.g., convergent evolution of transcriptional regulation of gene circuits in bacteria and fungi; see [2]).

Convergence is also recognized in ecological assemblages, for example in high altitude plant communities of the Andes, Alps, and Himalayas [3]. In fact, the homogeneity of vegetation in geographically distant biomes was discussed early in the history of ecology $[4,5]$. The resemblance of high altitude plant communities, or whole communities of plants, birds and lizards in the Mediterranean climates of California, Chile, South Africa, and the Mediterranean Basin, are examples of community convergence, defined as the physiognomic similarity of assemblages of co-occurring plants or animals resulting from comparable physical and biotic selective pressures [6-8]. Community convergence focuses on community structure and functional traits, but does not explicitly investigate interactions among species.

\section{Convergent interactions}

We define convergent interactions as the independent emergence of multispecies interactions with similar physiological or ecological functions. We define ecological function as the role a species plays in an interaction, community or ecosystem; for example, the excretion of essential amino acids by an endosymbiotic bacterium, or the decomposition of dead leaves by an 
insect detritivore. Our definition of convergent interactions is purposefully broad, and can be used to generate hypotheses about many kinds of ecological relationships. The concept might be especially useful when thinking about symbioses and microbes; for example, the ecology of microbial gut communities in independently evolved herbivores with similar gut morphology, including kangaroos and bighorn sheep [9]. Using convergent interactions as a framework for studying associations is likely to bring new clarity to nascent and dynamic studies of symbioses among microbes and other organisms (reviewed in [10]).

Convergent interactions are often associated with convergently evolved morphological structures, and specialized morphologies can aid in identification of ecological functions. For example, any fungus forming a "Hartig net" within a root tip is likely participating in an ectomycorrhizal mutualism with a plant [11]. Moreover, research on convergent interactions in one location can illuminate similar reciprocal selective pressures acting in analogous systems. For example, experiments with ants and ant-plants in Africa are likely to inform understanding of independently evolved ants and ant-plants in South America or Asia, not unlike using a "prior" in Bayesian inference.

We suggest that explicitly recognizing convergent interactions will provide a heuristic method to predict: 1) the functions of multiple, associated species, such as the metabolic capacities of microbes in an herbivore gut; 2) the ecological role of a symbiosis involving newly discovered or poorly described species, such as an ectomycorrhizal symbiosis recently found in a tropical habitat; and 3) selective pressures acting in one system based on data from a different system, such as among ant-plants found on different continents. Although convergence of multispecies interactions has been implicitly discussed in recent papers (e.g., [12-14]), the concept has never before been explicitly defined or formally explored. 


\section{Situating convergent interactions}

Our use of convergent interactions differs from current uses of convergent evolution and community convergence. Convergent evolution is defined strictly by phylogeny, and concerns individual species, not interactions. By contrast, convergent interactions focuses on the ecology and behaviors of multiple interacting species; moreover, the independent evolution of all of the interacting species is not required. For example, symbioses of two oak species with distantly related and independently evolved lineages of ectomycorrhizal fungi (e.g. truffles and boletes) can still be considered convergent even though the capacity of the oaks to form ectomycorrhizal associations is a synapomorphy: the associated fungi evolved the ectomycorrhizal habit independently. Community convergence describes similarities in the distribution, diversity, and morphologies of geographically disparate sets of co-occurring species in relation to similarities of their habitats (e.g., shrubs or lizards from California and Chile [6,7]), but does not specifically address interspecific interactions. Typically, community convergence focuses on a particular guild. By contrast, convergent interactions emphasizes relationships among multiple organisms and trophic levels, and often across different kingdoms. In certain circumstances, convergent interactions can appear as community convergence, for example if the mammalian gut is defined purely as a habitat and not as part of an organism. However, we think that an association among living organisms (e.g., bacteria and a human gut) will have fundamentally different evolutionary dynamics than an association of organisms with an abiotic environment (e.g., bacteria and a sewer pipe), because of the potential for coevolution.

A different framework, the geographic mosaic of coevolution, is useful for understanding how natural selection and coevolutionary processes differ among populations [15]. By contrast, 
convergent interactions encompasses interactions among groups of different species emerging independently from different lineages and in different regions of the world (e.g., ant-plant interactions in Africa, Southeast Asia, and South America). Convergent interactions takes a broader perspective than the geographic mosaic of coevolution, because it compares different groups of species across regions; however, geographic mosaics likely act within each group of species in a region (e.g., within Kenyan ant-plant interactions).

Last, convergent interactions also differs from analyses of phylogenetic community ecology. Phylogenetic community ecology examines how species are phylogenetically and phenotypically clustered or over-dispersed within a community, and typically explores whether these patterns are caused by competition or evolutionary convergence of similar traits [16]. Analyses of phylogenetic community ecology normally are done within one phylogenetic clade, and most often within a particular region; oak trees in Florida are a salient example [17]. By contrast, an analysis of convergent interactions might compare the interspecific interactions of organisms of different phylogenetic clades across geographically distant systems; for example, among trees and ectomycorrhizal symbionts from North America and Australia (Figure 1A).

Convergent evolution is best understood in a phylogenetic framework, where trait evolution can be traced through ancestral nodes and the independence of a particular trait can be explored [18,19]. However, the ancestral nodes of entire communities (however defined) cannot be modeled with phylogenies, because of the continual exchange of species among habitats within a region [20]. Nor can interactions be modeled with phylogenies, unless the interactions involve hosts and symbionts with strict vertical transmission [21]. Methods for assessing convergent evolution or community convergence can only be applied to convergent interactions when one set of interacting partners are reduced to continuous traits (Boxes 1 and 2). Network 
analyses with dynamic models that allow for coevolution among interacting species might be useful avenues for developing future methods to assess convergent interactions (Box 2).

\section{Examples of convergent interactions}

To develop the concept of convergent interactions, we discuss five examples involving microbial symbioses, mutualisms, and trophic interactions. The examples illustrate how convergent interactions can be used to predict species' functions, ecological relationships, and selective pressures in novel systems. Because we are interested in convergence, we focus on similarities among the interactions; however, documenting differences will also be useful, particularly for understanding how phylogenetic constraints act within evolutionary lineages (Box 3). We note that in any discussion of convergence, "similarity" requires clear definition [8]. At fine scales, for example when species are identified, communities might appear to be random assemblages [22], but at coarser scales, for example when functional groups are identified, convergent patterns emerge [23]. We identify the appropriate scale and measure of similarity for each example.

Our first three examples focus on associations between microorganisms and animals or plants. Molecular techniques have greatly increased knowledge of microbial diversity and functions. For example, we now know that gut bacteria influence human weight, nutrition, and immune function [24]; bacterial and yeast endosymbionts provide insects with nutrition and protection (reviewed in [25]); and fungal endophytes deter plant pathogens and herbivores [2628]. However, the majority of the world's microbes - and their interactions and functionsremain difficult to characterize. A focus on convergent interactions will generate hypotheses to explain observed patterns of microbial species diversity and function. 
Bacterial communities in vertebrate guts illustrate how convergent interactions can be used to estimate community composition and functional repertoire based on the morphology and diet of an animal. Gut bacteria living within the digestive systems of animals assist in digestion of complex carbohydrates, provide vitamins, detoxify compounds, facilitate the maturation of the vertebrate immune system, and protect against some pathogens by interfering with other microbes [29]. Among vertebrates, mammals (especially herbivorous ruminants) have particularly dense and diverse communities of gut microbes. The ancestors of mammals were carnivorous [30], but the herbivorous habit is extremely successful: $80 \%$ of mammals alive today are herbivores, with herbivores present in 11 of 20 mammalian orders [30].

Communities of gut bacteria in mammals differ from free-living microbial communities, and reflect phylogenetic history, morphology, and host diet [9,31]. Among herbivorous mammals, gut morphology is correlated with fecal microbiota composition: foregut and hindgut fermenters have different microbial communities, regardless of the hosts' evolutionary relationships [31]. While foregut fermentation evolved separately in ungulates, rodents, marsupials, primates, and birds [30], the bacterial gut community of the hoatzin (the only avian foregut fermenter) is more similar to the gut community of a cow than it is to that of a chicken [32]. Ant and termite-eating vertebrates similarly show convergence of gut microbial communities; in this case, diet is probably the major influence [33]. Gut microbiomes are strongly influenced by both gut morphology and host diet, and distantly related hosts with similar diets tend to independently acquire organisms from the same bacterial phyla [31]. Does relatedness translate to function? The functional repertoires of fecal bacteria isolated from herbivores and carnivores can be predicted from phylogenetic measurements of 
bacterial species assemblages [12]. Gut microbiota of herbivores predominantly produce enzymes for amino acid biosynthesis, whereas gut microbiota of carnivores produce more enzymes involved in amino acid degradation. Bacteria from herbivores, even independently evolved herbivores, generally build amino acids; conversely, bacteria from carnivores generally break down proteins [12]. Host diet appears to cause convergence of function, as well as identity.

Convergent interactions are a better descriptor of these relationships than community convergence. Analysis with community convergence would omit the functional nature of the interactions while focusing on environmental filtering of otherwise randomly assembled groups of species.

Ectomycorrhizae illustrate how morphologies can be used to identify convergent interactions, even when the associations involve undescribed species. Mycorrhizae are symbioses between fungi and plants: the fungi supply scarce resources to plants in exchange for carbon [11]. Ectomycorrhizal (ECM) associations involve both ascomycete and basidiomycete fungi, and are found in every terrestrial ecosystem.

ECM symbioses evolved as recently as $50 \mathrm{Mya}[34,35]$. The associations evolved repeatedly and independently in the ascomycetes and basidiomycetes [11]; in the latter, ECM associations evolved at least 14 times in at least eight orders (Box 1). Among these 14 origins, eight of the de novo symbioses involved angiosperms, whereas six involved gymnosperms [36].

In spite of their independent origins, and in line with the concept of convergent interactions, ECM morphology is convergent across lineages (Figure 1A). ECM associations are defined by three features: 1) a fungal sheath or mantle around a root; 2) a network of hyphae (the Hartig net) within the epidermal and cortical cells of the root; and 3) a mycelium extending from 
the root through soil [11]. Once the diagnostic morphologies of ectomycorrhizae are recognized, broad aspects of the plant-fungal metabolic exchange are clear, even if the particular species are undescribed. Thus, recognition of ECM morphologies facilitates discovery of mutualisms involving undescribed species of fungi, especially where biodiversity is poorly characterized (e.g. [37]).

\section{Insects that grow fungi and use antibiotic-producing bacteria to defend their} gardens from antagonistic organisms illustrate that presence of "third parties" in a symbiosis can be inferred from convergent interactions. Species of ants, beetles, termites, and gall midges all grow fungi as a food source in enclosed "garden" chambers. Associations of insects and fungi have evolved repeatedly and independently, across different orders of both groups [38]. In these convergent interactions, fungi provide nutrition and a nesting substrate for the insects, while insects provide material for fungal decomposition, protected growing spaces, and transportation to new locations.

Antibiotic-producing bacteria are a common third party associated with fungus-growing ants, beetles, and termites. For example, ants have developed associations with Actinobacteria multiple times, with independent acquisitions in two genera [39,40]. The Actinobacteria are maintained on the ants' cuticles, and target the garden parasite Escovopsis [39-41]. Two species of bark beetle also associate with Actinobacteria to suppress antagonistic fungi $[42,43]$. A different bacterial lineage appears to play the same role within termite symbioses: a Bacillus species in the phylum Firmicutes appears to selectively target fungi antagonistic to the fungal cultivar farmed by the termite Macrotermes natalensis [44]. The functional gene profiles of the bacteria associated with fungus-growing ants, beetles, and termites are convergent [14], with 
roughly equivalent physiological potentials, even though the insects are from three different orders, and the fungal cultivars are from two different phyla [14] (Box 1).

These independently evolved, close associations of fungus-growing insects and antifungal-producing bacteria provide a powerful model that can be used to understand other symbioses. In contrast to the symbioses involving ants, beetles, and termites, the fungus-growing habit of the gall midges (from the tribes Lasiopterini and Asphondyliini of the family Cecidomyiidae) is poorly understood. Gall midges associate with fungi in what are thought to be obligate nutritional symbioses $[45,46]$, but gall midges and their associated fungi are rarely been studied. Nonetheless, convergent interactions among bacteria, fungi, and ants, beetles, or termites suggests that selective antibiotic-producing bacteria also will be found in the fungal gardens of gall midges. In these systems, convergence is defined as hosting bacterial taxa with a common function: the production of antimicrobial compounds capable of protecting a target cultivar.

Food webs in carnivorous pitcher plants enable us to explore convergent interactions among entire micro-ecosystems. In three unrelated plant families on three different continents, the pitcher-shaped carnivorous organs are formed from a single, modified leaf $[47,48]$. Pitcher plants use extrafloral nectaries to attract insect prey. The pitchers have slippery interior surfaces, and enzymes within pitchers digest prey to access resources that otherwise are scarce in the low nutrient soils where these species grow. Once the pitchers open, food webs of insects, arachnids, protozoa, rotifers, bacteria, and fungi form in the water-filled pools of many pitcher plant species [49]. 
Diverse organisms live in the pitchers; although many are host-specific [50], functions are often similar. For example, both Sarracenia (Ericales: Sarraceniaceae) and Nepenthes (Caryophyllales: Nepenthaceae) pitchers host predators, filter feeders, and detritivores [51]. The food webs of pitchers from these different families on different continents are more like each other than they are like the food webs of other aquatic microcosms, even if the microcosms are in the same habitat as the pitchers [50]. Convergence might be influenced by the plants' internal chemistry, which is similar among all pitcher plant lineages and is controlled to some extent by the plant [51-53].

Pitchers are elegant models that can be used to test for convergent interactions among microecosystems. For example, knowing that predators, filter feeders, and detritivores are common to well-studied Sarracenia and Nepenthes species suggests hypotheses about the presence, absence, and ecological relationships of communities not only within newly described or poorly studied pitcher plant species, but also in other phytotelms [54,55]. Microbes actively decompose captured prey in Sarracenia purpurea pitchers [52,56], likely increasing available resources, and we hypothesize that microbes with similar functional repertoires will be active in the microbiomes of other Sarracenia and Nepenthes species, as well as in pitchers of the rarely studied pitcher-plant Cephalotus follicularis. As with the insect-fungal-bacterial associations, convergent interactions in these systems are defined by the presence or absence of species with a specific function in the food web; like the bacterial communities of herbivore guts, similarity can be measured using metabolic capacities, such as microbial enzymes for protein decomposition.

Ant-plant mutualisms result from similar selective pressures. Ants have associated intimately with plants since at least the diversification of flowering plants almost 100 Mya 
[57,58]. Different groups of plants have evolved specialized interactions with ants, providing food and nest sites in exchange for protection from herbivores, pathogens, and competing plants [59]. More than $25 \%$ of all plant families secrete extra-floral nectar, and plants from at least 20 different families produce hollow thorns or stems ("domatia") that provide ants with suitable nesting sites; many also are provisioned with food bodies rich in protein or fat [60].

Classic examples of ant-plants include African Vachellia (Acacia) species, which grow large swollen thorns to house ant colonies [61]; Southeast Asian Macaranga species, which host ants within hollow swollen stems [62,63]; and Neotropical Acacia and Cecropia species, which have either swollen thorns similar to African Vachellia (Acacia) or hollow stems similar to Macaranga [64] (Figure 1B, Box 1). Ant-plants tend to grow quickly and in high-light environments, and the associated ants tend to be aggressive towards other organisms, even removing nearby vegetation to enable the host plant to compete more effectively for light and space [65]. As with our example of convergent interactions among ectomycorrhizae, morphology signals a particular kind of ant-plant interaction; a newly discovered species of plant with swollen hollow stems, food bodies, and extra-floral nectaries is very likely to be in a long-term association with ants.

Because the benefits and costs of ant-plant mutualisms have been demonstrated experimentally in some systems, selective pressures shaping the evolution of ant-plants that have not yet been investigated can be inferred [66]. For example, when the plant-ants Pseudomyrmex ferruginea are present on Vachellia (Acacia) cornigera, the plants experience decreased herbivory and increased survival while the ants gain nutrition and nesting space [67]. Ant inhabitants compete fiercely for control of domatia and easy access to food provided by antplants [59]. Hosting ants can be costly for plants, because of the resources devoted to producing 
extra-floral nectar and shelter structures. Protecting plants also can be costly for ants. Some ants attack herbivores such as elephants that they cannot kill and eat [68]. In spite of these costs, the repeated evolution of ant-plant relationships in all tropical regions of the world likely is caused by the mutual strong selective pressures of herbivory on plants, and competition for food and nesting space on ants [59].

\section{Mechanisms mediating the emergence of convergent interactions}

Why and how do convergent interactions emerge? No organism lives in isolation, and most organisms require both their own genetic information and functions provided by other species to survive and reproduce [69]. Phylogenetic constraints can limit potential trait space. In some circumstances, evolving a close interaction with another organism will be simpler than evolving a new metabolic function. For example, prokaryotes are the only organisms able to make nitrogenases, enabling them to fix atmospheric nitrogen [70]. Plants are generally nitrogen limited, but have never evolved the ability to fix nitrogen, probably because of both phylogenetic and metabolic constraints. Instead, many plants have evolved symbioses with different groups of nitrogen-fixing bacteria [71] (Table 1). Evolving a symbiosis with bacteria appears to be simpler than evolving a new metabolic function. However, even the evolution of the symbiosis appears constrained within subsets of the larger phylogeny of plants. Even though greater access to fixed nitrogen would probably increase the fitness of most plants, only four orders of rosids associate with nitrogen fixing bacteria [72]. Constraints on the evolution of interactions remain poorly understood (Box 3). Dependence on another organism clearly entails risks [73], but in certain contexts the same kinds of associations emerge repeatedly and independently. Exploring 
convergent interactions will likely provide new insights into how phylogenetic constraints have shaped and continue to shape the evolution of multispecies associations.

Convergent interactions are unlikely to result from neutral, stochastic processes. Losos (2011) discusses three alternative mechanisms that would result in apparent convergent evolution. Traits might be convergent as a result of coincidence (a spurious correlation due to random chance), or exaptation (a feature that originally evolved in response to a different selective pressure), or because traits are a correlated response to selection on a different character (when similar constraints are shared by taxa, responses can also be shared) [18]. An evolved interaction between species is unlikely to result from random chance. While an interaction may be interpreted as involving exaptation-e.g. mutualisms have evolved from parasitisms [74] and symbionts have switched hosts [75] — if the same changes happen repeatedly and independently among different, geographically disparate groups of organisms, then natural selection is likely at play. It is also difficult to imagine convergent interactions emerging as a result of selection on correlated traits. But however unlikely, whether convergent interactions are ever the result of neutral processes remains an open question (Box 3).

\section{Conclusions}

Interactions within different systems can be defined as convergent if the interactions: 1) evolved independently; 2) involve organisms from different trophic levels; and 3) are functionally similar. Convergent interactions are easier to identify when they are found in geographically separated ecosystems, or occur among organisms with convergently evolved morphological or ecological traits (e.g., herbivores with hindguts or insects that grow fungi). 
Convergent interactions provide evidence that natural selection can repeatedly favor certain types of interspecific relationships, and in fitness landscapes involving multiple species, key interactions can represent adaptive peaks. Recognizing convergent interactions provides a framework to generate hypotheses about ecological relationships among poorly studied taxa and to identify potential selective pressures structuring the diversity and function of multispecies interactions across kingdoms. Extrapolating from known to unknown might be most straightforward in systems where natural selection has reciprocally shaped all interacting parties, as coevolving partners are likely to be exerting specific and similar selective pressures on each other.

Our examples reflect our own experiences working with microbes, mutualisms, and food webs, but the concept of convergent interactions will also be useful for understanding other types of interactions. For example, convergence appears to be a feature of parasitic fig wasp communities associated with tree species in Africa, Australia and America [76] (Table 1). Species richness differs among the different communities, but the proportions of individual insects within various functional groups are similar across the communities, and these three geographically separated, multi-trophic systems fit the definition of convergent interactions.

Convergent interactions provide a useful framework for interpreting recent discoveries of functional convergence patterns, particularly those involving microbes and animals. For example, like the complex bacterial communities associated with mammalian hindguts and fungus-growing insects, functional equivalence and evolutionary convergence have also been found in the bacterial communities of sponges [13] (Table 1). An explicit focus on convergent interactions will almost certainly illuminate similar functional relationships influencing community assembly in a myriad of other systems. 


\section{Box 1. Tools and metrics for identifying convergent interactions}

In some cases, different groups of interacting organisms do not share common ancestors, and convergent interactions are obvious. In other cases, convergent interactions are less obvious but can be identified using a combination of ecological and phylogenetic methods.

\section{Method 1: Natural History}

The simplest way to identify convergent interactions is to describe 1) the interaction, 2) the species involved, and 3) the relationships among species of each interacting group. For example, interactions of ant-plants (from 19 different families) and their ant inhabitants (from 5 different subfamilies) involve the exchange of nesting space and food for protection from herbivores. Phylogenetically independent associations are found on different continents (Figure 1). The common ancestor of Macaranga and Cecropia trees was not a myrmecophyte, and the common ancestor of Crematogaster and Azteca ants was not an obligate tree-associated ant. Each interaction evolved independently.

\section{Method 2: Phylogenetic Molecular Dating Analysis}

Phylogenetic methods are critical for dating the relative ages of clades, and can be used to identify convergent interactions. A necessary postulate is that an interaction cannot evolve before the interacting organisms exist. Certain clades of fungi, for example the Cantharellales, evolved before the appearance of pines or flowering plants in the rosid clade [36] (Box Figure I). Pines and rosids do not share an ectomycorrhizal ancestor, but plants from each clade are ectomycorrhizal. Therefore pine-Cantharellales symbioses must have evolved independently 
from rosid-Cantharellales symbioses. A phylogeny of agaricomycete fungi and plants identifies at least eight independent origins of associations between Agaricomycota and angiosperms, and six independent origins between Agricomycota and gymnosperms [36] (Box Figure I).

Phylogenetic dating is straightforward when interactions involve two organisms, but more difficult to use in systems involving three or more species.

\section{Method 3: Ordination}

Ordination can identify convergence among microbial communities and their hosts by clustering communities according to functional similarity (Box Figure II). Ordination methods require information about 1) host taxonomy; 2) host traits (e.g., gut morphology or fungal cultivation); and 3) the presence, abundance, and functional traits of microbes. Clusters can be identified visually and tested using permutational multivariate analysis of variance [77]. When communities associated with hosts from different lineages cluster together according to a convergent host trait, the interactions of the hosts and their communities are recognized as convergent [14] (Box Figure II).

\section{Box 2. Potential methods for exploring patterns of convergent interactions}

With sufficient data, recently developed methods for mapping trait evolution onto phylogenies [78] or for quantifying the strength of convergent evolution [79] might emerge as useful resources for identifying and measuring convergent interactions. However, to use these tools, one set of interacting partners must be redefined as a trait of interest or measure of diversity. For example, continuous functional traits (e.g., cellulose degradation) and bacterial gut community diversity measures (e.g., phylogenetic beta diversity) could be mapped onto a host 
phylogeny (e.g., mammals) using SURFACE [78]. SURFACE identifies convergent

evolutionary regimes and then uses simulations to test whether there is more convergence than would be expected by chance. Using this approach, one could test whether herbivores have associated convergently with bacterial communities having high cellulose-degradation capacities. Adding the recently developed Wheatsheaf index can enable quantification of the strength of convergence, by measuring phenotypic similarity while penalizing for phylogenetic relatedness [79].

Network analyses also can be used to describe convergent patterns of interactions across multispecies communities. To date, analyses exploring convergence across multiple networks have focused on very broad network structure; for example, when looking at different kinds of networks, plant-animal mutualistic networks are more highly nested than food-webs, regardless of the type of mutualism [80]. Within networks, selection on a complementary trait between trophic levels can lead to trait convergence within a trophic level [81]. The connection between coevolution and trait convergence in mutualistic networks is complex, with results depending on the strength of selection [82]. Similar network approaches likely can be extended to comparisons across multiple networks to identify convergent interactions, where different species in different systems have similar functional roles. For example, two systems with convergent interactions might have network topologies that are more similar than expected by chance alone, if different organisms fulfilling the same ecosystem function exhibit similar measures of centrality.

Advances in metagenomic sequencing and stable isotope analysis (particularly stable isotope probing [83]) can provide additional information on functional genes and trophic levels for small, difficult to observe organisms such as microbes and invertebrates $[84,85]$. New technologies and emerging protocols should allow microbes to be incorporated into existing food 
webs of plants and animals, which can then be used to explore convergence across entire ecosystem networks.

\section{Acknowledgments}

Our research was supported by an NSF Graduate Research Predoctoral Fellowship and NSF Doctoral Dissertation Grant DEB-1400982 (to L.S.B.), NSF grants DEB 1144056 and DEB 1237491 (to A.M.E), a grant from the HFSP (to A.P.), and a Templeton FQEB grant (to N.E.P. and A.P). We thank Jon Sanders, Charles Davis, Dan Sternof Beyer, Tom Miller, and Matt Lau for helpful discussions and suggestions. We appreciate the feedback from three anonymous reviewers, which greatly improved the manuscript. 
References:

1 Darwin, C. (1859) On the origin of species, Murray

2 Conant, G.C. and Wagner, A. (2003) Convergent evolution of gene circuits. Nat. Genet. 34, 264-266

3 Humboldt, von, A. and Bonpland, A. (1805) Essai sur la géographie des plantes, Chez Levrault, Schoell et Compagnie, Libraries

4 Clements, F.E. (1916) Plant Succession: An Analysis of the Development of Vegetation, Carnegie Institution of Washington

5 Clements, F.E. (1936) Nature and structure of the climax. J. Ecol. 24, 252-284

6 Mooney, H.A. and Dunn, E.L. (1970) Convergent evolution of Mediterranean-climate evergreen sclerophyll shrubs. Evolution 24, 292-303

7 Cody, M.L. and Mooney, H.A. (1978) Convergence versus nonconvergence in mediterranean-climate ecosystems. Ann. Rev. Ecol. Syst. 9, 265-321

8 Samuels, C.L. and Drake, J.A. (1997) Divergent perspectives on community convergence. Trends Ecol. Evol. (Amst.) 12, 427-432

9 Ley, R.E. et al. (2008) Worlds within worlds: evolution of the vertebrate gut microbiota. 6, 776-788

10 McFall-Ngai, M. et al. (2013) Animals in a bacterial world, a new imperative for the life sciences. Proc. Natl. Acad. Sci. U.S.A. 110, 3229-3236

11 Smith, S.E. and Read, D.J. (2010) Mycorrhizal Symbiosis, Third Edition. Academic Press.

12 Muegge, B.D. et al. (2011) Diet drives convergence in gut microbiome functions across mammalian phylogeny and within humans. Science 332, 970-974

13 Fan, L. et al. (2012) Functional equivalence and evolutionary convergence in complex communities of microbial sponge symbionts. Proc. Natl. Acad. Sci. U.S.A. 109, E1878-87

14 Aylward, F.O. et al. (2014) Convergent bacterial microbiotas in the fungal agricultural systems of insects. MBio 5, e02077

15 Thompson, J.N. (2005) The geographic mosaic of coevolution, University of Chicago Press.

16 Cavender-Bares, J. et al. (2009) The merging of community ecology and phylogenetic biology. Ecol. Letters 12, 693-715

17 Bares, J.C. et al. (2004) Phylogenetic overdispersion in Floridian oak communities. Am. Nat. 163, 823-843

18 Losos, J.B. (2011) Convergence, adaptation, and constraint. Evolution 65, 1827-1840

19 Stayton, C.T. (2008) Is convergence surprising? An examination of the frequency of convergence in simulated datasets. J. Theor. Biol. 252, 1-14

20 Schluter, D. and Ricklefs, R.E. (1993) Convergence and the regional component of species diversity. In Species diversity: historical and geographical perspectives (Ricklefs, R. E. and Schluter, D., eds), pp. 230-240, University of Chicago Press

21 Funk, D.J. et al. (2000) Intraspecific phylogenetic congruence among multiple symbiont genomes. Proc. R. Soc. B 267, 2517-2521

22 Gleason, H.A. (1926) The individualistic concept of the plant association. Bulletin of the Torrey Botanical Club 53, 7-26

23 Fukami, T. et al. (2005) Species divergence and trait convergence in experimental plant community assembly. Ecol. Letters 8, 1283-1290

24 Kau, A.L. et al. (2011) Human nutrition, the gut microbiome and the immune system. Nature 474, 327-336

25 Douglas, A.E. (2015) Multiorganismal insects: diversity and function of resident 
microorganisms. Annu. Rev. Entomol. 60, 17-34

26 Clay, K. (1988) Fungal endophytes of grasses: a defensive mutualism between plants and fungi. Ecology 69, 10-16

27 Arnold, A.E. et al. (2003) Fungal endophytes limit pathogen damage in a tropical tree. Proc. Natl. Acad. Sci. U.S.A. 100, 15649-15654

28 Bittleston, L.S. et al. (2011) Endophytic fungi reduce leaf-cutting ant damage to seedlings. Biol. Lett. 7, 30-32

29 Walter, J. et al. (2011) Host-microbial symbiosis in the vertebrate gastrointestinal tract and the Lactobacillus reuteri paradigm. Proc. Natl. Acad. Sci. U.S.A. 108, 4645-4652

30 Stevens, C.E. and Hume, I.D. (1995) Comparative physiology of the vertebrate digestive system, Cambridge University Press

31 Ley, R.E. et al. (2008) Evolution of mammals and their gut microbes. Science 320, 16471651

32 Godoy-Vitorino, F. et al. (2011) Comparative analyses of foregut and hindgut bacterial communities in hoatzins and cows. ISME J. 6, 531-541

33 Delsuc, F. et al. (2014) Convergence of gut microbiomes in myrmecophagous mammals. Mol. Ecol. 23, 1301-1317

34 LePage, B.A. et al. (1997) Fossil ectomycorrhizae from the middle Eocene. Am. J. Bot. 84, $410-412$

35 Beimforde, C. et al. (2011) Ectomycorrhizas from a Lower Eocene angiosperm forest. New Phytol. 192, 988-996

36 Hibbett, D.S. and Matheny, P.B. (2009) The relative ages of ectomycorrhizal mushrooms and their plant hosts estimated using Bayesian relaxed molecular clock analyses. BMC Biol. 7, 13

37 Peay, K.G. et al. (2009) Potential link between plant and fungal distributions in a dipterocarp rainforest: community and phylogenetic structure of tropical ectomycorrhizal fungi across a plant and soil ecotone. New Phytol. 185, 529-542

38 Mueller, U.G. et al. (2001) The origin of the attine ant-fungus mutualism. Q. Rev. Biol. 76, $169-197$

39 Cafaro, M.J. and Currie, C.R. (2005) Phylogenetic analysis of mutualistic filamentous bacteria associated with fungus-growing ants. Can. J. Microbiol. 51, 441-446

40 Barke, J. et al. (2010) A mixed community of actinomycetes produce multiple antibiotics for the fungus farming ant Acromyrmex octospinosus. BMC Biol. 8, 109

41 Currie, C.R. et al. (2006) Coevolved crypts and exocrine glands support mutualistic bacteria in fungus-growing ants. Science 311, 81-83

42 Scott, J.J. et al. (2008) Bacterial protection of beetle-fungus mutualism. Science 322, 63

43 Cardoza, Y.J. et al. (2006) Bacteria in oral secretions of an endophytic insect inhibit antagonistic fungi. Ecol. Entomol. 31, 636-645

44 Um, S. et al. (2013) The fungus-growing termite Macrotermes natalensis harbors bacillaene-producing Bacillus sp. that inhibit potentially antagonistic fungi. Sci. Rep. 3, 3250

45 Heath, J.J. and Stireman, J.O. (2010) Dissecting the association between a gall midge, Asteromyia carbonifera, and its symbiotic fungus, Botryosphaeria dothidea. Entomol. Exper. Applic. 137, 36-49

46 Rohfritsch, O. (2008) Plants, gall midges, and fungi: a three-component system. Entomol. Exper. Applic. 128, 208-216 
47 Arber, A. (1941) On the morphology of the pitcher-leaves in Heliamphora, Sarracenia, Darlingtonia, Cephalotus, and Nepenthes. Ann. Bot. 5, 563-578

48 Albert, V.A. et al. (1992) Carnivorous plants: phylogeny and structural evolution. Science 257, 1491-1495

49 Frank, J.H. (1983) Phytotelmata, Plexus Pub.

50 Kitching, R.L. (2000) Food webs and container habitats, Cambridge University Press.

51 Adlassnig, W. et al. (2011) Traps of carnivorous pitcher plants as a habitat: composition of the fluid, biodiversity and mutualistic activities. Ann. Bot. 107, 181-194

52 Bradshaw, W.E. and Creelman, R.A. (1984) Mutualism between the carnivorous purple pitcher plant and its inhabitants. Am. Midl. Nat. 112, 294-304

53 An, C.-I. et al. (2001) Plasma-membrane H+-ATPases are expressed in pitchers of the carnivorous plant Nepenthes alata Blanco. Planta 212, 547-555

54 Srivastava, D.S. et al. (2004) Are natural microcosms useful model systems for ecology? Trends Ecol. Evol. (Amst.) 19, 379-384

55 Ellison, A.M. et al. (2003) The evolutionary ecology of carnivorous plants. Adv. Ecol. Res. $33,1-74$

56 Butler, J.L. et al. (2008) Linking the brown and green: nutrient transformation and fate in the Sarracenia microecosystem. Ecology 89, 898-904

57 Wilson, E.O. and Hölldobler, B. (2005) The rise of the ants: a phylogenetic and ecological explanation. Proc. Natl. Acad. Sci. U.S.A. 102, 7411-7414

58 Moreau, C.S. et al. (2006) Phylogeny of the ants: diversification in the age of angiosperms. Science 312, 101-104

59 Davidson, D.W. and McKey, D. (1993) The evolutionary ecology of symbiotic ant-plant relationships. J. Hym. Res. 2, 13-83

60 Bronstein, J.L. (2006) The contribution of ant- plant protection studies to our understanding of mutualism. Biotropica 30, 150-161

61 Young, T.P. et al. (1997) Ants on swollen-thorn acacias: species coexistence in a simple system. Oecologia 109, 98-107

62 Fiala, B. et al. (1989) Studies of a South East Asian ant-plant association: protection of Macaranga trees by Crematogaster borneensis. Oecologia 79, 463-470

63 Quek, S.-P. et al. (2007) The geography of diversification in mutualistic ants: a gene's-eye view into the Neogene history of Sundaland rain forests. Mol. Ecol. 16, 2045-2062

64 Janzen, D.H. (1969) Allelopathy by myrmecophytes: the ant Azteca as an allelopathic agent of Cecropia. Ecology 50, 147-153

65 Rico-Gray, V. and Oliveira, P.S. (2007) The ecology and evolution of ant-plant interactions, University of Chicago Press

66 Rosumek, F.B. et al. (2009) Ants on plants: a meta-analysis of the role of ants as plant biotic defenses. Oecologia 160, 537-549

67 Janzen, D.H. (1966) Coevolution of mutualism between ants and acacias in Central America. Evolution 20, 249-275

68 Mayer, V.E. et al. (2014) Current issues in the evolutionary ecology of ant-plant symbioses. New Phytol. 202, 749-764

69 Thompson, J.N. (1999) The Evolution of Species Interactions. Science 284, 2116-2118

70 Raymond, J. et al. (2004) The natural history of nitrogen fixation. Mol. Biol. Evol. 21, 541554

71 Franche, C. et al. (2009) Nitrogen-fixing bacteria associated with leguminous and non- 
leguminous plants. Plant Soil 321, 35-59

72 Gherbi, H. et al. (2008) SymRK defines a common genetic basis for plant root endosymbioses with arbuscular mycorrhiza fungi, rhizobia, and Frankia bacteria. Proc. Natl. Acad. Sci. U.S.A. 105, 4928-4932

73 Colwell, R.K. et al. (2012) Coextinction and persistence of dependent species in a changing world. Annu. Rev. Ecol. Evol. Syst. 43, 183-203

74 Weeks, A.R. et al. (2007) From parasite to mutualist: Rapid evolution of Wolbachia in natural populations of Drosophila. PLoS Biol. 5, 997-1005

75 Wolfe, B.E. et al. (2010) Distribution and abundance of the introduced ectomycorrhizal fungus Amanita phalloides in North America. New Phytol. 185, 803-816

76 Segar, S.T. et al. (2013) Convergent structure of multitrophic communities over three continents. Ecol. Letters 16, 1436-1445

77 Anderson, M.J. (2001) A new method for non- parametric multivariate analysis of variance. Austral Ecol. 26, 32-46

78 Ingram, T. and Mahler, D.L. (2013) SURFACE: detecting convergent evolution from comparative data by fitting Ornstein- Uhlenbeck models with stepwise Akaike Information Criterion. Methods Ecol. Evol. 4, 416-425

79 Arbuckle, K. et al. (2014) A simple measure of the strength of convergent evolution. Methods Ecol. Evol. 5, 685-693

80 Bascompte, J. et al. (2003) The nested assembly of plant-animal mutualistic networks. Proc. Natl. Acad. Sci. U.S.A. 100, 9383-9387

81 Guimarães, P.R. et al. (2011) Evolution and coevolution in mutualistic networks. Ecol. Letters 14, 877-885

82 Nuismer, S.L. et al. (2013) Coevolution and the Architecture of Mutualistic Networks. Evolution 67, 338-354

83 Dumont, M.G. and Murrell, J.C. (2005) Stable isotope probing - linking microbial identity to function. Nat. Rev. Micro. 3, 499-504

84 Layman, C.A. et al. (2012) Applying stable isotopes to examine food-web structure: an overview of analytical tools. Biol. Rev. 87, 545-562

85 Haig, S.-J. et al. (2015) Stable-isotope probing and metagenomics reveal predation by protozoa drives E. coli removal in slow sand filters. ISME J. 9, 797-808

86 Rosas-Guerrero, V. et al. (2014) A quantitative review of pollination syndromes: do floral traits predict effective pollinators? Ecol. Letters 17, 388-400

87 Renner, S.S. and Schaefer, H. (2010) The evolution and loss of oil-offering flowers: new insights from dated phylogenies for angiosperms and bees. Phil. Trans. R. Soc. B 365, 423435

88 Dunlap, P.V. et al. (2007) Phylogenetic analysis of host--symbiont specificity and codivergence in bioluminescent symbioses. Cladistics 23, 507-532

89 Pankey, M.S. et al. (2014) Predictable transcriptome evolution in the convergent and complex bioluminescent organs of squid. Proc. Natl. Acad. Sci. U.S.A. 111, E4736-42 
Figure 1: Convergent interactions in ectomycorrhizae and ant-plants

Legend: A) Examples of ectomycorrhizal symbioses. Left: A pine tree (Pinus [a gymnosperm]) and the basidiomycete Amanita. Right: Southern Beech (Nothofagus [an angiosperm]) and the ascomycete Elaphomyces. Though neither trees nor fungi are closely related, the root tips (enlarged in circles) of both symbioses have similar morphologies: a mantle of fungal hyphae covering the root, highly branched structures between root cells (the Hartig net), and extraradical mycelia extending from the mantles into surrounding soils.

B) Examples of ant-plants and plant-ants. Left: Macaranga (Malpighiales) and Crematogaster (Myrmicinae). Right: Cecropia (Rosales) and Azteca (Dolichoderinae). Though neither the plants nor ants are closely related, both trees have domatia in hollow stems where ants rear larvae and tend hemipterans, and both produce food bodies consumed by ants. In turn, the ants protect their trees from herbivores. Illustrations by L. S. Bittleston.

Box 1, Figure I: Multiple independent evolutions of ectomycorrhizal symbioses Legend: Multiple independent origins of ectomycorrhizal (ECM) associations between agaricomycete fungi and angiosperms or gymnosperms (yellow or orange stars, respectively). Rosids and pines do not share a common ancestor associated with ectomycorrhizal fungi, and as these taxa evolved after certain clades of ectomycorrhizal agaricomycete fungi, the symbiotic interactions must have arisen independently. Modifed from [36] under Creative Commons Attribution (CC-BY) License @ 2009 Hibbett and Matheny. 
Box 1, Figure II: Functional convergence in bacterial communities of fungus-growing insects Legend: Metagenomic functional profiles of bacterial communities associated with convergently evolved insect-fungal symbioses cluster separately from environmental or other host associated communities. A) Principal coordinate analysis of bacterial community metagenomes annotated using the Protein Families (Pfam) database. B) Simplified phylogeny of select insect orders. Orders including insects with insect-fungal symbioses shown in (A) are highlighted in blue. Modifed from [14] under Creative Commons Attribution-Noncommercial-ShareAlike 3.0 Unported license @ 2014 Aylward et al. 


\section{Box 3: Outstanding Questions}

- How common are convergent interactions?

- When do organisms evolve the capacity for a particular function versus evolving an interaction with a different organism that can already perform that function?

- How often are convergent interactions evolutionary innovations, and the cause of increased niche breadth and perhaps ultimately adaptive radiations?

- How do the population dynamics of species affect the emergence of convergent interactions? The demographics of individuals among populations may speed or slow the emergence of interactions.

- What constrains the evolution of convergent interactions? Does convergence require particular environments, for example habitats lacking in a key resource, or traits with simple genetic underpinnings? How do organisms' developmental and phylogenetic constraints affect the emergence of convergent interactions?

- Can convergent interactions result solely from neutral processes?

- What can we learn from identifying differences among convergent interactions, for example, differences among ectomycorrhizal symbioses that have evolved independently?

- What new methods are required to identify, understand, and quantify convergent interactions? 
Table 1. In addition to the five examples detailed in the text, other potential examples of convergent interactions include:

\begin{tabular}{|l|l|}
\hline Interaction & Description \\
\hline $\begin{array}{l}\text { Rosid plants and } \\
\text { nitrogen-fixing } \\
\text { bacteria }\end{array}$ & $\begin{array}{l}\text { Plants in four orders of the rosid clade of angiosperms have } \\
\text { close, prolonged associations with nitrogen-fixing bacteria in } \\
\text { the Alphaproteobacteria, Betaproteobacteria, and } \\
\text { Actinobacteria [71]. The single evolution of a gene necessary } \\
\text { for nodulation likely allowed plants to form associations } \\
\text { with bacteria [72], and the different phyla of bacteria likely } \\
\text { acquired nitrogenase genes via horizontal transmission [70]; } \\
\text { however, the interactions of the plants with different groups } \\
\text { of bacteria seem to have emerged independently. }\end{array}$ \\
\hline $\begin{array}{l}\text { Different } \\
\text { functional } \\
\text { groups of wasps } \\
\text { living within figs }\end{array}$ & $\begin{array}{l}\text { Communities of parasitoid, pollinator, and galler wasps from } \\
\text { different evolutionary lineages live in figs in Australia, Africa, } \\
\text { and South America [76]. }\end{array}$ \\
\hline $\begin{array}{l}\text { Sponges with } \\
\text { bacterial } \\
\text { symbionts }\end{array}$ & $\begin{array}{l}\text { The different microbial communities that associate with } \\
\text { divergent groups of sponges are functionally equivalent [13]. }\end{array}$ \\
\hline $\begin{array}{l}\text { Plant pollination } \\
\text { syndromes }\end{array}$ & $\begin{array}{l}\text { Plants from different lineages have converged on floral traits } \\
\text { that attract particular groups of pollinators. A recent } \\
\text { quantitative meta-analysis finds strong evidence that } \\
\text { pollination syndromes predict the most efficient pollinators, } \\
\text { particularly when pollinators are bats, bees, birds, or moths } \\
\text { [86]. }\end{array}$ \\
\hline $\begin{array}{l}\text { Plants } \\
\text { producing floral } \\
\text { oils and oil- } \\
\text { collecting bees }\end{array}$ & $\begin{array}{l}\text { Oil-producing flowers evolved at least 28 times within 11 } \\
\text { different plant families, and oil-foraging behavior evolved at } \\
\text { least 7 times within bees [87]. }\end{array}$ \\
\hline $\begin{array}{l}\text { Marine } \\
\text { organisms and } \\
\text { bioluminescent } \\
\text { bacteria }\end{array}$ & $\begin{array}{l}\text { Bioluminescent symbioses with bacteria in the Vibrionaceae } \\
\text { family appear to have evolved independently in four teleost } \\
\text { fish orders [88] and in two squid families [89]. }\end{array}$ \\
\hline
\end{tabular}


Figure 1
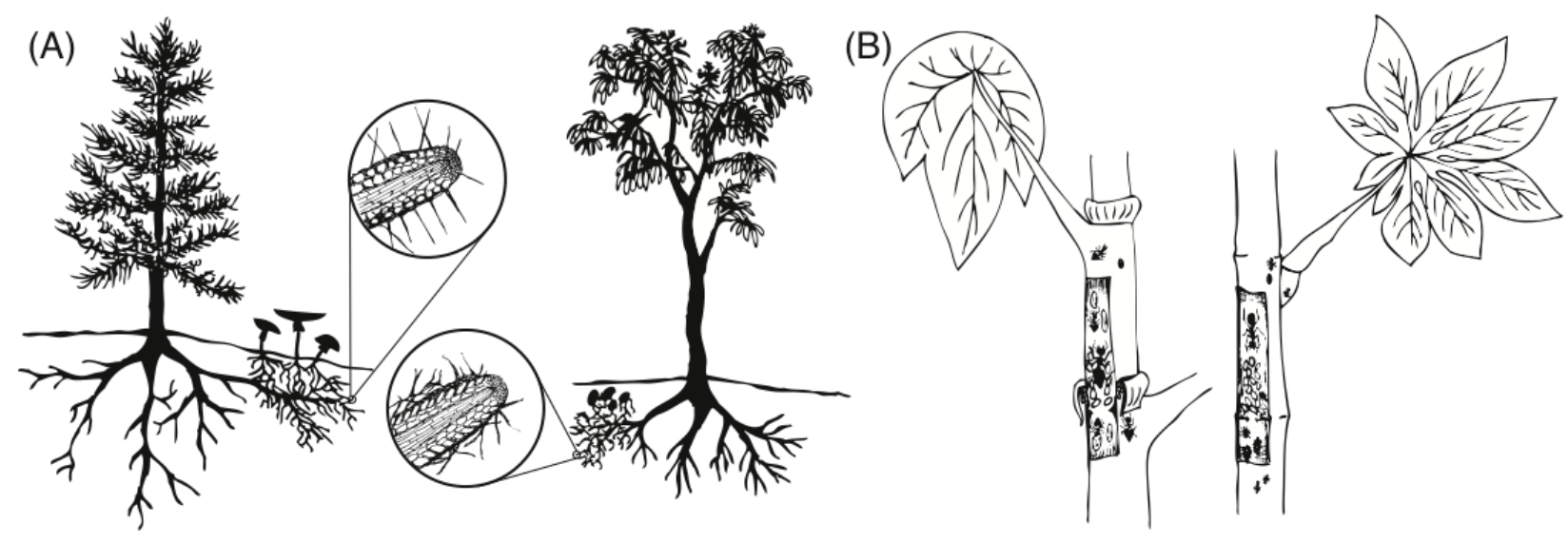
Box 1, Figure I

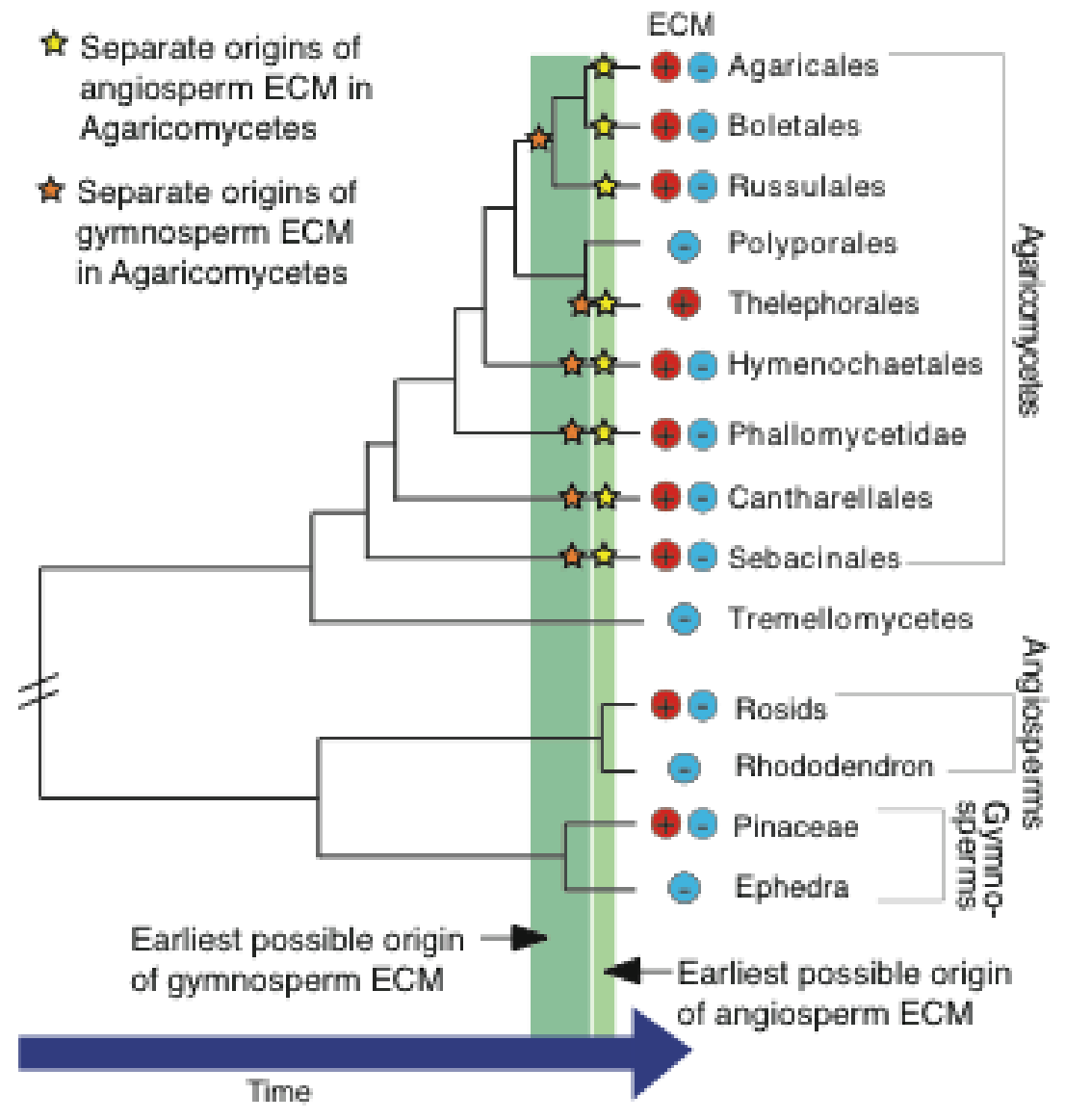


Box 1, Figure II

(A)

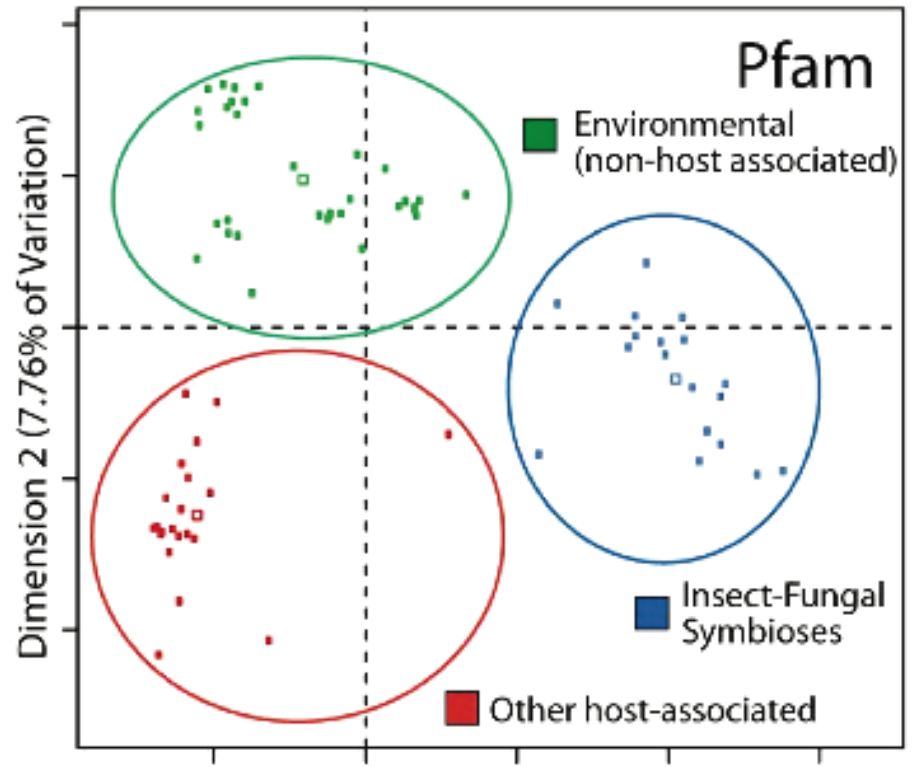

(B)

Dimension 1 ( $12.25 \%$ of Variation)

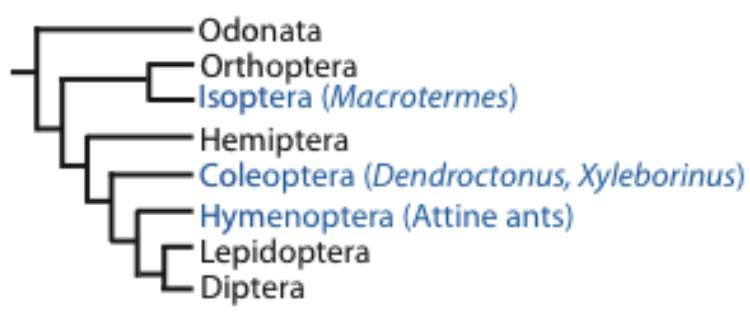

